\title{
The Effect of Estradiol on Renal Function in Reversible and Irreversible Unilateral Ureteral Obstruction in Rats
}

\author{
Zahra Lak ${ }^{1}$, Akbar Vahdati ${ }^{1}$, Mehdi Nematbakhsh ${ }^{2,3,4, *}$ \\ ${ }^{1}$ Department of Biology, Shiraz Branch, Islamic Azad University, Shiraz, Iran \\ ${ }^{2}$ Water and Electrolytes Research Center, Isfahan University of Medical Sciences, Isfahan, Iran \\ ${ }^{3}$ Department of Physiology, Isfahan University of Medical Sciences, Isfahan, Iran \\ ${ }^{4}$ Isfahan MN Institute of Basic and Applied Sciences Research, Isfahan, Iran \\ *Corresponding author. E-mail: nematbakhsh@med.mui.ac.ir
}

Received date: May 3, 2018; Revised date: Jul 24, 2018; Accepted date: Aug 2, 2018

\section{Abstract}

$\mathrm{B}$ ACKGROUND: The ureteral obstruction (UO) is the most common clinical disorders. This study was designed to investigate the renoprotective effect of estradiol in unilateral UO (UUO) and reversible UUO (RUUO).

METHODS: Eighty-four ovareictomized Wistar rats were assigned into 14 groups. Group 1 was sham operated group. All the groups 2-14 were subject to UUO, however they received additional treatments. Group 2-4 received test substances (vehicle, 0.1 or $0.05 \mathrm{mg} / \mathrm{kg}$ of estradiol) and sacrificed after 3 days. Group 5-7 received test substances and after 3 days followed by RUUO (obstruction removal) and after one day post RUUO were sacrificed. Group 8-9 followed by RUUO after 3 days and simultaneously received estradiol and after one day post RUUO were sacrificed. Group 10-12 followed by RUUO after 3 days and simultaneously received test substances and after 3 days post RUUO were sacrificed. Group 13-14 received test substances followed by RUUO and received test substances again and after 3 days post RUUO were sacrificed.

RESULTS: The estradiol reduced body weight significantly $(p<0.05)$ in UUO, and the uterus weight (UW) increased significantly by estradiol $(p<0.05)$. The increased serum levels of blood urea nitrogen $(\mathrm{BUN})$ and creatinine $(\mathrm{Cr})$, and kidney weight $(\mathrm{KW})$ induced by UUO $(p<0.05)$ were not attenuated by estradiol. Estradiol treatment did not alter the levels of BUN, $\mathrm{Cr}, \mathrm{KW}, \mathrm{Cr}$ clearance $(\mathrm{CrCl})$, urine sodium excretion and urine flow when compared with control.

CONCLUSION: Although the protective role of estradiol in cardiovascular system is well accepted, however our findings suggest that its protection during UUO or after RUUO in renal system cannot be certain.

KEYWORDS: estradiol, ureteral obstruction, renal function, rat

Indones Biomed J. 2018; 10(3): 263-9

\section{Introduction}

Ureteral obstruction (UO) is one of the most clinical disorder in the progression of renal dysfunction. $(1,2) \mathrm{UO}$ reduces the glomerular filtration rate (GFR) that leads to natriuresis, sodium and water excretion disturbances.(3) In order to restore the kidney function after unilateral UO (UUO), the obstruction must be removed either by drug or surgery. The surgery itself may accompany with alteration of renal medullary plasma flow and fluid reabsorption.(4) The UUO induced inflammation and tissue damage are resulted from stress oxidative formation.(5)

The antioxidants supplementation is one of best and well documented treatment to decrease the stress oxidative. In addition, the female sex hormone estrogen has been known as an endogenous antioxidant that its protective role in cardiovascular system has been accepted in women before menopause. The protective role of this hormone against chronic kidney disease also was reported (6), and 
the protection mechanism may related to glomerulosclerosis and interstitial tubular fibrosis prevention (7). Mao, et al., performed UUO in rats after 3 weeks of estradiol treatment (as prophylaxis), and the GFR and kidney tissue damage were evaluated about two weeks later, and they concluded that estradiol affected renal function in UUO model.(8) However, the short time effect of estradiol in UUO and after UUO removal (reversible UUO, RUUO) need to be studied. Based on epidemiological study that estrogen therapy improves GFR and blood pressure in postmenopausal women (9), there is hypothesized that estradiol could protect the kidney function against UUO and RUUO. To test this hypothesis, renal function makers were assessed in UUO and RUUO in ovariectomized estradiol treated rats.

\section{Methods}

This study was performed on 84 ovariectiomized female $(180 \pm 20 \mathrm{~g})$ Wistar rats, and it was approved in advance by the Isfahan University of Medical Sciences Ethics Committee (No. IR.MUI.REC.1396.2.094 and IR.MUI. REC.1396.2.096).

\section{Ovariectomy}

The animals were anesthetized with chloral hydrate (450 $\mathrm{mg} / \mathrm{kg}$ ) (Merck, Darmstadt, Germany). The incision was performed in suprapubic region, and the ovaries were removed with care. The ovariectomized animals were kept in animal cages for one week as a recovery period.

To collect urine from manipulated kidney, at the sacrifice day the right kidney was removed (nephrectomy), and after the recovery time, the animals were placed in standard metabolic cages for 6 hours to collect the urine for the measurements. Finally, the animals were sacrificed humanly with anesthetic drug, and the kidney and uterus were removed and weighted rapidly.

\section{UUO and RUUO}

After recovery period, the rats were anesthetized again, and the incision was made on the abdominal skin, the left kidneys were pulled out gently and the ureter was isolated from other surrounding tissues while the right kidney remained intact. The ureter was obstructed with 3-0 nylon suture. The kidneys were returned back to abdominal cavity. In order to perform RUUO model, the animals were anesthetized again 3 days after UUO, left kidney and obstructed ureter were exposed and the tie around the ureter was released carefully.

\section{Experimental Groups}

The experimental groups were assigned as following: 1) Group 1 (sham operated) was subjected to surgical procedure without UUO and sacrificed 3 days

Table 1. The summary of study design.

\begin{tabular}{ccccccc}
\hline Group & n & \multicolumn{5}{c}{ Time } \\
\cline { 3 - 6 } & & Day 1 & Day 7 & Day 10 & Day11 & Day 13 \\
\hline 2 & 6 & OV & $\begin{array}{c}\text { Surgical procedure } \\
\text { without UUO }\end{array}$ & S & NA & NA \\
3 & 6 & OV & UUO + vehicle & S & NA & NA \\
4 & 6 & OV & UUO + Es0.1 & S & NA & NA \\
5 & 6 & OV & UUO + Es0.5 & S & NA & NA \\
6 & 6 & OV & UUO + vehicle & RUUO & S & NA \\
7 & 6 & OV & UUO + Es0.5 & RUUO & S & NA \\
8 & 6 & OV & UUO & RUUO + Es0.1 & S & NA \\
9 & 6 & OV & UUO & RUUO + Es0.5 & S & NA \\
10 & 6 & OV & UUO & RUUO + vehicle & No intervention & S \\
11 & 6 & OV & UUO & RUUO + Es0.1 & No intervention & S \\
12 & 6 & OV & UUO & RUUO + Es0.5 & No intervention & S \\
13 & 6 & OV & UUO + Es0.1 & RUUO + Es0.1 & No intervention & S \\
14 & 6 & OV & UUO + Es0.5 & RUUO + Es0.5 & No intervention & S \\
\hline
\end{tabular}

OV: Ovariectomy; UUO: Unilateral ureteral obstruction; ES0.1: $0.1 \mathrm{mg} / \mathrm{kg}$ of estradiol treatment; ES0.5: 0.5 $\mathrm{mg} / \mathrm{kg}$ of estradiol treatment; RUUO: Unilateral ureteral obstruction removal ; S: Sacrifice; NA: not alive. 
later; 2) Group 2-4 were subjected to UUO and received vehicle, $0.1 \mathrm{mg} / \mathrm{kg}$ of estradiol, or $0.5 \mathrm{mg} / \mathrm{kg}$ of estradiol respectively, and sacrificed 3 days later; 3 ) Group 5-7 were subjected to UUO and received vehicle, $0.1 \mathrm{mg} / \mathrm{kg}$ of estradiol, or $0.5 \mathrm{mg} / \mathrm{kg}$ of estradiol respectively, but 3 days later, the obstruction was removed (named RUUO), and the animals were sacrificed one day post RUUO; 4) Group 8 and 9 were treated as group 6 and 7 except they received estradiol $(0.1$ or $0.5 \mathrm{mg} / \mathrm{kg})$ after RUUO and sacrificed one day post RUUO; 5) Group 10-12 were subjected to UUO, and 3 days later the obstruction was removed and the animals were treated with vehicle, $0.1 \mathrm{mg} / \mathrm{kg}$ estradiol, or $0.5 \mathrm{mg} / \mathrm{kg}$ of estradiol respectively and sacrificed 3 days post RUUO; and 6) Group 13 and 14 were treated as group 11 and 12 except that they received estradiol both at the day of UUO and at the day of RUUO. The summary of groups design is shown in Table 1.

\section{Blood Samples and Measurements}

Blood samples were taken via heart puncture after urine collection and stored in $-20^{\circ} \mathrm{C}$. The levels of urine and serum creatinine $(\mathrm{Cr})$ and blood urea nitrogen (BUN) were determined using quantitative diagnostic kits (Pars Azmoon, Tehran, Iran) and automatic analyzer RA-1000 (Technicon, Dublin, Ireland). Urine and plasma sodium (Na) concentrations were measured by phlamephotomer assay. The $\mathrm{Cr}$ clearance $(\mathrm{CrCl})$, urine $\mathrm{Na}$ excretion $(\mathrm{UNaV})$ and urine flow (UF) also were determined. After sacrificing, the left kidney and uterus were removed carefully and the kidney weight $(\mathrm{KW})$ and uterus weight (UW) were determined using digital scale. The KW and UW were normalized based on $100 \mathrm{~g}$ of body weight.

\section{Statistical Analyses}

The data were reported as mean \pm standard error of mean (SE). The ANOVA for repeated measures was applied to analyses the body weight change between the groups. One way ANOVA and Tukey as a post hoc test were employed to compare the kidney function markers between the groups. The $p$-value less than 0.05 was considered as significant.

\section{Results}

\section{Body Weight Changes}

The alteration of body weight (BW) during the experiment is shown in Figure 1. The upper panel shows the percentage (\%) change of BW in the animals subjected to UUO treated with vehicle or estradiol and compared with sham group.
The \% change of BW in sham group was significantly different from estradiol treated groups $(p<0.05)$. No significant differences between the groups were seen in the middle and lower panels indicated that estradiol treatment did not alter BW changes.

\section{The Effect of Estradiol on UUO}

The UUO alone increased the serum levels of BUN and $\mathrm{Cr}$, and kidney weight $(\mathrm{KW})$ significantly $(p<0.05)$. The ovaries were removed by ovariectomy, however the estradiol increased the UW statistically $(p<0.05)$ as expected, but it did not alter the serum level of BUN and $\mathrm{Cr}$, and $\mathrm{KW}$ when compared with control group (Figure 2). No urine was collected in this situation.

\section{The Effect of Estradiol in RUUO Models}

The 3 days of UUO followed by 24 hours of RUUO in rats treated with different estradiol dosages did not alter the levels of BUN, $\mathrm{Cr}, \mathrm{CrCl}, \mathrm{UF}, \mathrm{UNaV}$ and $\mathrm{KW}$ when compared with control group (Figure 3, left panel). In addition, the 3 days of UUO followed by 3 days of RUUO in rats treated with different estradiol dosages also did not alter the mentioned markers (Figure 3, right panel). However, the UW increased significantly in all estradiol treated groups as expected $(p<0.05)$ (Figure 3).

\section{Discussion}

The adverse effect of UUO even after RUUO is a serious problem in clinic, and special care is needed to least the adverse side effects during or after RUUO. Estrogen as an antioxidant and cardiovascular protectant agent in female always has been nominated. The current study was designed to evaluate the effect of estradiol on renal function markers in conditions of UUO and RUUO in rats. The estradiol was administered at the time of obstruction, after RUUO or both, and the kidney functions markers were evaluated. It seems that the protective role of estradiol in renal system was not certain.

Previously, it is reported that UUO is accompanied with increasing of serum BUN and Cr levels (10), reduction of GFR about $20-70 \%(11,12)$, decreasing of tubular injury and interstitial fibrosis (13), reduction of $\mathrm{UNaV}$ and urine osmolality (14), and increasing of fibronectin expression (15). In our study, the serum level of BUN and $\mathrm{Cr}$ were increased by UUO possibly by renal fibrosis or GFR reduction. We did not measure the $\mathrm{CrCl}$ in $\mathrm{UUO}$ alone groups due to lack of urine flow. It seems this disturbance 
UUO (3 days)

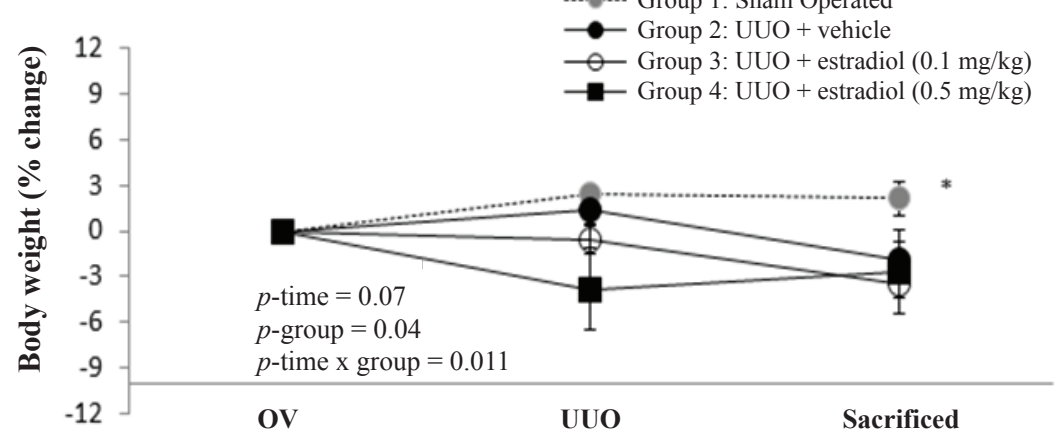

UUO (3 Days + RUUO (24 hours)

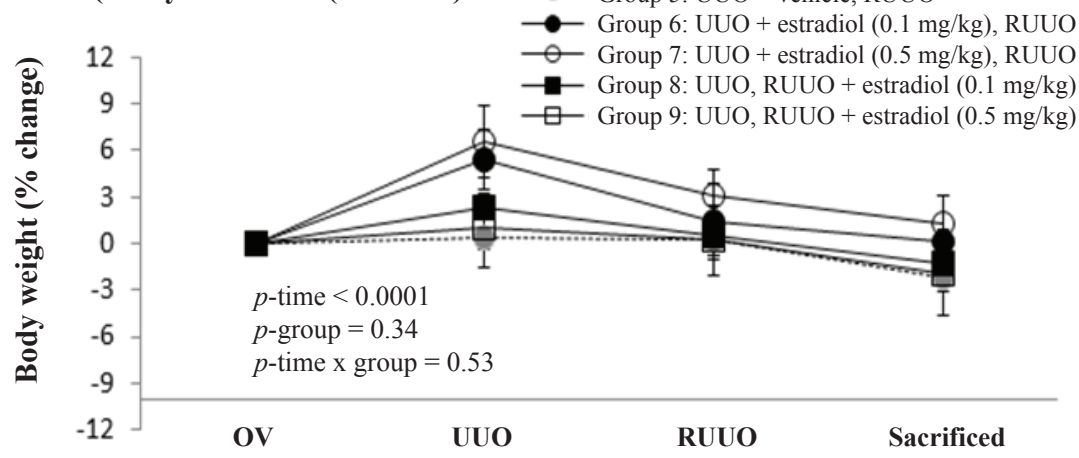

UUO (3 Days) + RUUO (3 days)

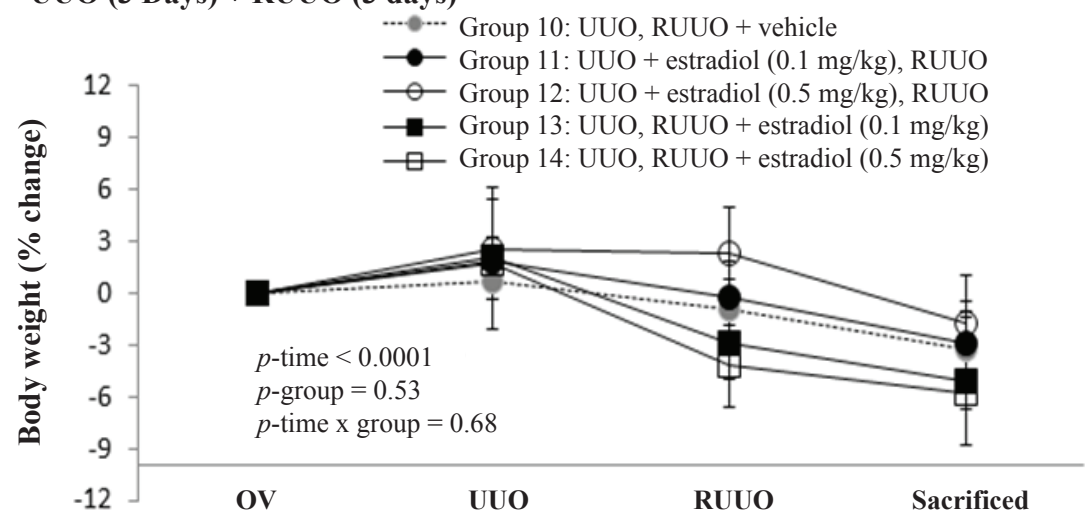

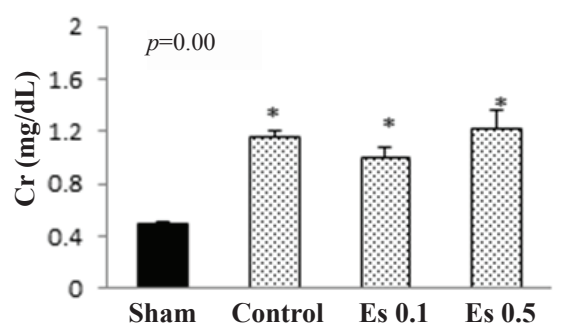

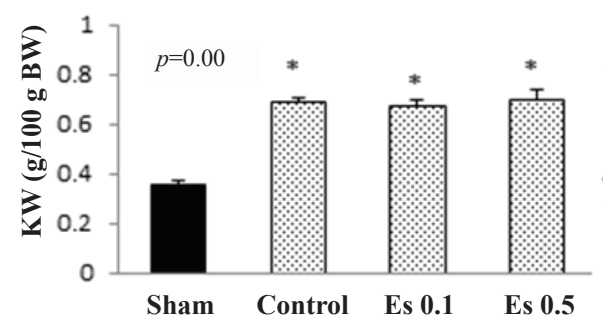

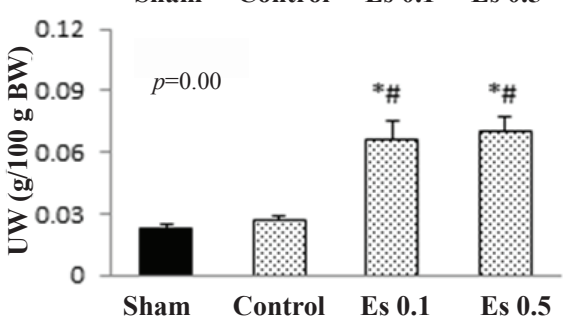

Figure 1. The percentage (\%) change of body weight (BW) in 14 experimental groups ( $n=6$ in each group). The upper panel shows the \% change of $\mathrm{BW}$ in animals subjected to unilateral ureteral obstruction (UUO) treated with vehicle or estradiol compared with sham group. These animals were sacrificed 3 days post obstruction. The $\%$ change of $\mathrm{BW}$ in sham group was significantly different from estradiol treated groups $(p<0.05)$. The middle panel indicates the $\%$ change of BW in animals subjected to UUO treated with vehicle or estradiol, but at 3 days post obstruction, the obstruction was removed, and these animals were sacrificed 24 hours post unilateral ureteral obstruction removal (RUUO) The lower panel shows the \% change of $\mathrm{BW}$ in animals subjected to UUO with and without estradiol treatment, but at 3 days post obstruction, the obstruction was removed accompanied with estradiol treatment and these animals were sacrificed 3 days post RUUO. Analyses of variance for repeated measure data indicated no significant difference between the groups in middle and lower diagrams. The star $\left(^{*}\right)$ indicates significant difference from groups 3 and 4 $(p<0.05)$. See the text for groups' detail.

Figure 2. The serum levels of blood urea nitrogen (BUN), creatinine (Cr), kidney weight $(\mathrm{KW}) / 100 \mathrm{~g}$ body weight $(\mathrm{BW})$ and ureter weight/100 $\mathrm{g} \mathrm{BW}$ (UW) in sham group (group 1), control group (group 2) and estradiol treated groups which received $0.1 \mathrm{mg} / \mathrm{kg}$ (Es0.1) or 0.5 $\mathrm{mg} / \mathrm{kg}$ (Es0.5) of estradiol (group 3 and 4) $(n=6$ in each group). All the groups except sham groups were subjected to unilateral ureteral obstruction (UUO). The $p$ values were obtained by one way ANOVA, and the symbols of (*) and (\#) showed significant difference from sham and control groups respectively $(p<0.05)$ using Tukey as post hoc test. 

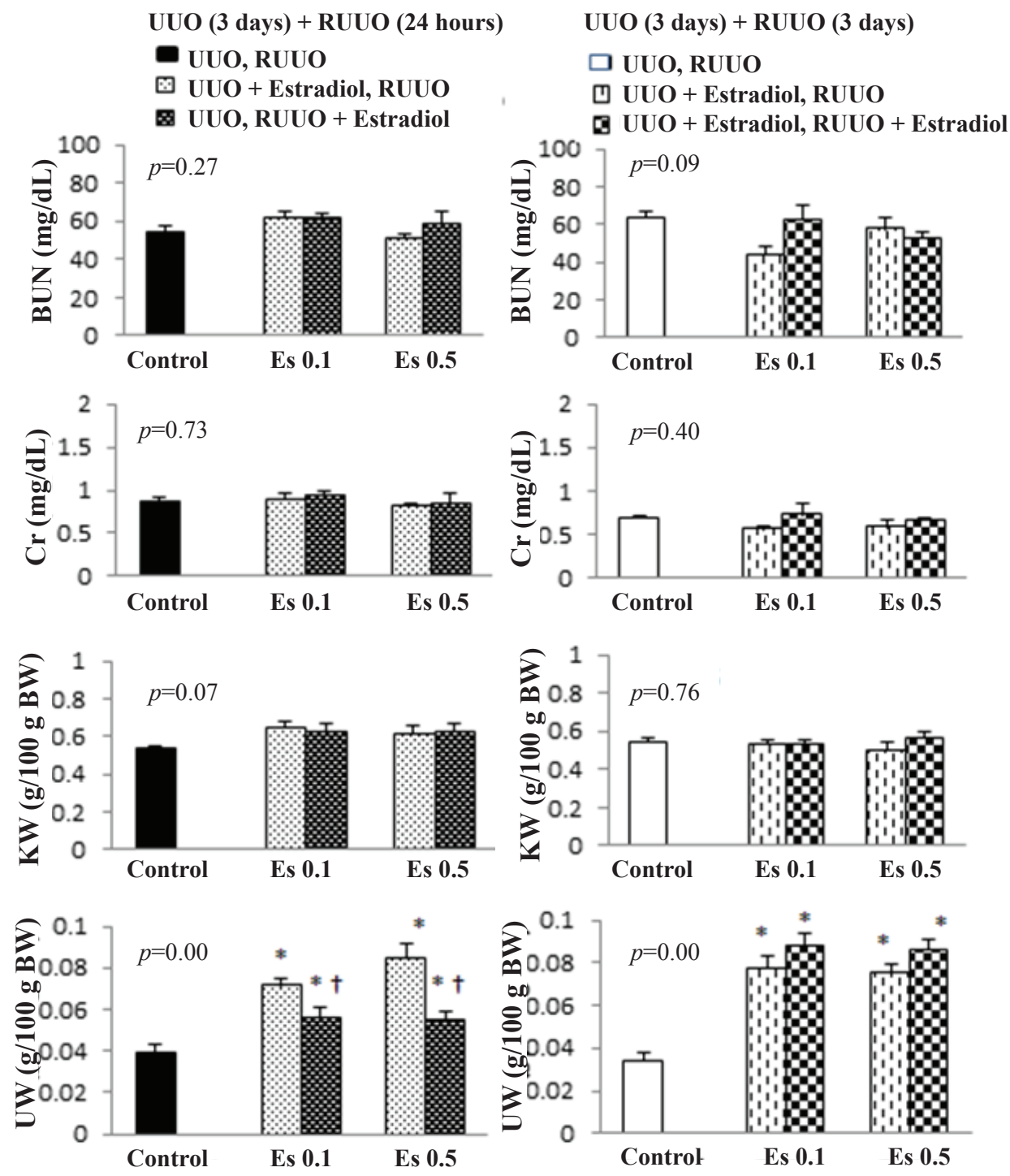

Figure 3. The serum levels of blood urea nitrogen (BUN), creatinine (Cr), kidney weight (KW)/ $100 \mathrm{~g}$ body weight (BW) and ureter weight/100 g BW (UW) in control groups (group 5 and 10) and estradiol treated groups which received $0.1 \mathrm{mg} / \mathrm{kg}$ (Es0.1) or 0.5 $\mathrm{mg} / \mathrm{kg}$ (Es0.5) of estradiol (groups 6-9 and groups 11-14) $(\mathbf{n}=\mathbf{6}$ in each group). All the groups were subjected to unilateral ureteral obstruction (UUO) for three day, and the obstruction was removed (called unilateral ureteral obstruction removal, RUUO) for 24 hours or 3 days. The $p$ values were obtained by one way ANOVA, and the symbols of $(*)$ or $(\dagger)$ show significant difference from control or adjacent group $(p<0.05)$ using Tukey as post hoc test.

decreased GFR and accumulated Cr or BUN in the body. Renal fibrosis due to UUO also causes damage to the kidney's main cells, which results decreasing of GFR and tubular reabsorption, and increasing of serum $\mathrm{Cr}$ levels.(16) Renin angiotensin system (RAS) also is another system that is disturbed by UUO. $(17,18)$ The RAS plays a great role in the adjustment of the hemodynamics in UUO model (19), and it has also been shown that after UUO, the local production of angiotensin II increased (20) which may result low renal blood flow (RBF) and GFR.
Estradiol is usually thought to be renoprotective. It is anti-apoptosis (21) and anti-inflammation $(22,23)$. In our model, the estradiol did not demonstrate an effective role on kidney functions markers. One possibility is related to estradiol treatment duration, because it is reported that estradiol had no effect on the serum levels of BUN and Cr, and $\mathrm{CrCl}$ in $\mathrm{UO}$ model on day 2 and 6 , but on day 16 the protective effect of estradiol on renal function was detected.(8) However, in this study we used different doses of estradiol to determine the short time effect of estradiol, 

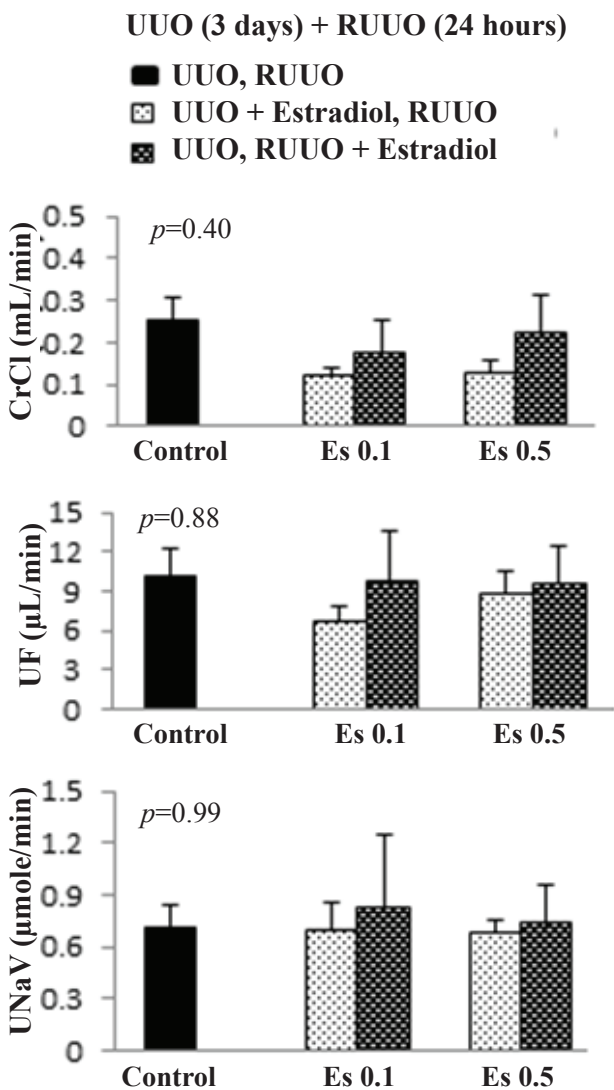

UUO (3 days) + RUUO (3 days)

$\square$ UUO, RUUO

๑ UUO + Estradiol, RUUO

UUO + Estradiol, RUUO + Estradiol
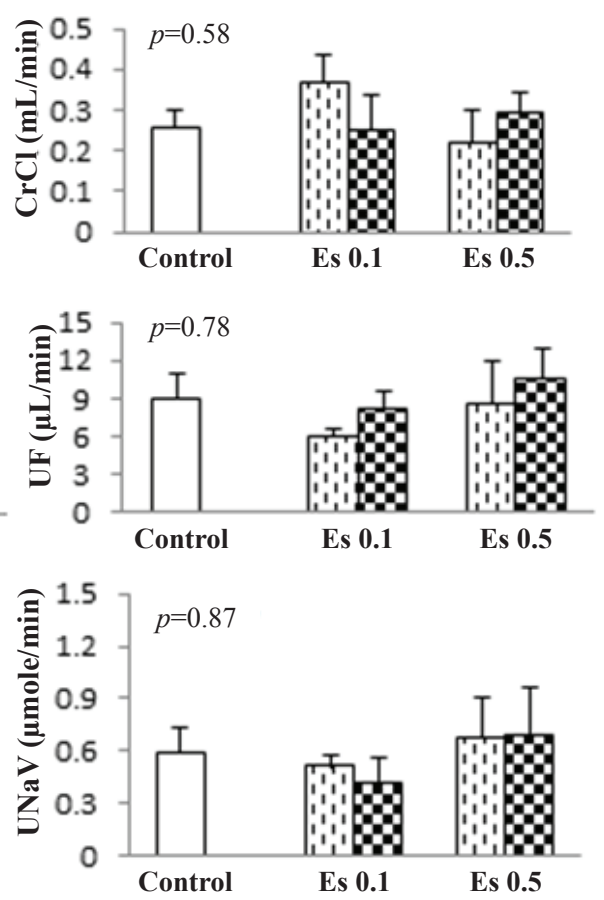

Figure 4. The creatinine clearance ( $\mathrm{CrCl}$ ), urine flow (UF) and urine sodium excretion (UNaV) in control groups (group 5 and 10) and estradiol treated groups which received $0.1 \mathrm{mg} / \mathrm{kg}($ Es0.1) or $0.5 \mathrm{mg} / \mathrm{kg}($ Es0.5) of estradiol (groups 6-9 and groups 11-14) $(\mathrm{n}=$ 6 in each group). All the groups were subjected to unilateral ureteral obstruction (UUO) for three day, and then obstruction was removed (called unilateral ureteral obstruction removal, RUUO) for 24 hours or 3 days. A one way ANOVA test shows no significant differences were detected between the groups.

because the estradiol effect may depend on treatment time and dosage. Our findings also did not demonstrate any considerable protective action of estradiol after RUUO. The RUUO eliminated the initial stimulus, but the interstitial damage may be remained. Chevalier, et al., reported that initial urinary tract injury was remained 1 month after the surgery.(24) Other study indicated that improving of the tubular function in obstructive kidney needs to more than 2 weeks after the RUUO.(25) Hasanshahi and Nematbakhsh reported that 3-days UUO decreased RBF and increased renal vascular resistances (RVR) in ipsilatral kidney.(26) It is also reported the significant increase of GFR at 72 hours after RUUO, while no change in $\mathrm{UNaV}$ shortly after RUUO was observed.(27) In a preliminary report founded that three months after 5-days of UUO in the neonatal rat, the GFR of the post obstructed kidney was reduced by $50 \%$ (28). Some of these findings were similar to our study; however our data did not confirm the protective effect of estradiol after RUUO possibly due to non-chronic treatment of estradiol.

\section{Conclusion}

Although estradiol is a well-known protective agent in cardiovascular system, however our findings suggest that the short time effect of different doses of estradiol on UUO or on RUUO models is not certain, and its protective effect may occur long time after RUUO while short-term injury induced by UUO progress even after RUUO.

\section{Acknowledgment}

This research was supported by Isfahan University of Medical Sciences (Grant \# 296094 \& 296096).

\section{References}

1. Klahr S. New insights into the consequences and mechanisms of renal impairment in obstructive nephropathy. Am J Kidney Dis. 1991; 18 : 689-99. 
2. Klahr S, Purkerson ML. The pathophysiology of obstructive nephropathy: The role of vasoactive compounds in the hemodynamic and structural abnormalities of the obstructed kidney. Am J Kidney Dis. 1994; 23: 219-23.

3. Klahr S, Harris K, Purkerson ML. Effects of obstruction on renal functions. Pediatr Nephrol. 1988; 2: 34-42.

4. Buerkert J, Martin D, Head M, Prasad J, Klahr S. Deep nephron function after release of acute unilateral ureteral obstruction in the young rat. J Clin Invest. 1978; 62: 1228-39

5. Dendooven A, Ishola Jr DA, Nguyen TQ, Van der Giezen DM, Kok RJ, Goldschmeding R, et al. Oxidative stress in obstructive nephropathy. Int J Clin Exp Pathol. 2011; 92: 202-10.

6. Cherikh W, Young C, Kramer B, Taranto S, Randall H, Fan PY. Ethnic and gender related differences in the risk of end-stage renal disease after living kidney donation. Am J Transplant. 2011; 11:1650-5.

7. Puri TS, Shakaib MI, Chang A, Mathew L, Olayinka O, Minto AW, et al. Chronic kidney disease induced in mice by reversible unilateral ureteral obstruction is dependent on genetic background. Am J Physiol Renal Physiol. 2010; 298: F1024-32.

8. Mao S, Xu H, Zou L, Xu G, Wu Z, Ding Q, et al. Estrogen preserves split renal function in a chronic complete unilateral ureteral obstruction animal model. Exp Ther Med. 2014;7:1555-62.

9. Fung MM, Poddar S, Bettencourt R, Jassal SK, Barrett-Connor E. A cross-sectional and 10-year prospective study of postmenopausal estrogen therapy and blood pressure, renal function, and albuminuria: the Rancho Bernardo Study. Menopause. 2011; 18: 629-37.

10. Wein AJ, Kavoussi LR, Novick AC, Partin AW, Peters CA. CampbellWalsh Urology: Expert Consult Premium Edition: Enhanced Online Features and Print, 4-volume set. New York: Elsevier; 2011.

11. Gillenwater J. The pathophysiology of urinary tract obstruction. In: Singh I, Strandhoy JW, Assimos DG. Campbell's Urology. New York: Elsevier; 1992. p.497-532.

12. Jun L, Tong G, Xu F, Renjie Z. Effect of salvianolic acid A and C compatibility on inflammatory cytokines in rats with unilateral ureteral obstruction. J Tradit Chin Med. 2015; 35: 564-70.

13. Li C, Wang W, Kwon TH, Knepper MA, Nielsen S, Frøkiær J. Altered expression of major renal $\mathrm{Na}$ transporters in rats with unilateral ureteral obstruction. Am J Physiol Renal Physiol. 2003; 284: F15566.

14. Topcu SO, Nørregaard R, Pedersen M, Wang G, Jørgensen TM, Frøkiær J. Regulation of aquaporins and sodium transporter proteins in the solitary kidney in response to partial ureteral obstruction in neonatal rats. Urol Int. 2011; 87: 94-104.

15. Shen Y, Miao N, Xu J, Gan X, Xu D, Zhou L, et al. Metformin prevents renal fibrosis in mice with unilateral ureteral obstruction and inhibits Ang II-induced ECM production in renal fibroblasts. Int J Mol Sci. 2016; 17: 146. doi: 10.3390/ijms17020146.
16. Liu H, Li W, He Q, Xue J, Wang J, Xiong C, et al. Mass spectrometry imaging of kidney tissue sections of rat subjected to unilateral ureteral obstruction. Sci Rep. 2017; 7: 41954. doi: 10.1038/ srep41954.

17. Hassanshahi J, Maleki M, Nematbakhsh M. Renin-angiotensin system and unilateral ureteral obstruction. Physiol Pharmacol. 2017: 7: 5764.

18. Hassanshahi J, Maleki M, Nematbakhsh M. Renal blood flow and vascular resistance responses to angiotensin II in irreversible and reversible unilateral ureteral obstruction rats; the role of angiotensin II type 1 and 2 receptors. J Nephropathol. 2018; 7: 5764.

19. Hvistendahl JJ, Pedersen TS, Djurhuus JC, Pedersen EB, Frøkiær J. Losartan attenuates renal vasoconstriction in response to acute unilateral ureteral occlusion in pigs. Urol Res. 2002; 30: 16977.

20. Durvasula RV, Petermann AT, Hiromura K, Blonski M, Pippin J, Mundel $\mathrm{P}$, et al. Activation of a local tissue angiotensin system in podocytes by mechanical strain1. Kidney Int. 2004; 65: 30-9.

21. Negulescu O, Bognar I, Lei J, Devarajan P, Silbiger S, Neugarten J. Estradiol reverses TGF- $\beta 1$-induced mesangial cell apoptosis by a casein kinase 2-dependent mechanism. Kidney Int. 2002; 62:198998.

22. Álvarez Á, Hermenegildo C, Issekutz AC, Esplugues JV, Sanz MJ. Estrogens inhibit angiotensin II-induced leukocyte-endothelial cell interactions in vivo via rapid endothelial nitric oxide synthase and cyclooxygenase activation. Circ Res. 2002; 91: 1142-50.

23. Mori M, Tsukahara F, Yoshioka T, Irie K, Ohta H. Suppression by $17 \beta$-estradiol of monocyte adhesion to vascular endothelial cells is mediated by estrogen receptors. Life Sci. 2004; 75:599-609.

24. Chevalier RL, Kim A, Thornhill BA, Wolstenholme JT. Recovery following relief of unilateral ureteral obstruction in the neonatal rat. Kidney Int. 1999; 55: 793-807.

25. Ito K, Chen J, El Chaar M, Stern JM, Seshan SV, Khodadadian JJ, et $a l$. Renal damage progresses despite improvement of renal function after relief of unilateral ureteral obstruction in adult rats. Am J Physiol Renal Physiol. 2004; 287: F1283-93.

26. Hassanshahi J, Nematbakhsh M. The role of Mas receptor on renal hemodynamic responses to angiotensin 1-7 in both irreversible and reversible unilateral ureteral obstruction rats. Adv Biomed Res. 2018; 7: 12. doi: 10.4103/abr.abr_176_17.

27. Gheissari A, Nematbakhsh M, Amir-Shahkarami SM, Alizadeh F, Merrikhi A. Glomerular filtration rate and urine osmolality in unilateral ureteropelvic junction obstruction. Adv Biomed Res. 2013; 2: 78. doi: 10.4103/2277-9175.120866.

28. Chevalier RL, Thornhill BA, Chang AY. Unilateral ureteral obstruction in neonatal rats leads to renal insufficiency in adulthood. Kidney Int. 2000; 58: 1987-95. 